\title{
Analysis of fire behaviour simulations over Spain with WRF-FIRE
}

\author{
Roberto San José* and Juan Luis Pérez
}

Environmental Software and Modelling Group,

Computer Science School,

Technical University of Madrid (UPM),

Campus de Montegancedo,

Boadilla del Monte, 28660 Madrid, Spain

Fax: +34-913367412

E-mail: roberto $($ fi.upm.es

E-mail: jlperez@ fi.upm.es

*Corresponding author

\section{Rosa M. González}

Department of Geophysics and Meteorology,

Faculty of Physics,

Complutense University of Madrid (UCM),

Ciudad Universitaria, 28040 Madrid, Spain

E-mail: rgbarras@igmail.com

\section{J. Pecci and Marino Palacios}

\author{
Indra S.A., \\ C/ Mar Egeo, 4, Pol. Industrial 1, \\ 28830 San Fernando de Henares, Madrid, Spain \\ E-mail: jpecci@indra.es \\ E-mail: mpalacios@indra.es
}

\begin{abstract}
Wildland fire spread and behaviour are complex phenomena owing to both the number of involved physico-chemical factors, and the non-linear relationship between variables. Spain is plagued by forest and brush fires every summer, when the extremely dry weather sets in along with high temperatures. The use of fire behaviour models requires the availability of high resolution environmental and fuel data; in the absence of real data, errors on the simulated fire spread can be compounded to affect the spatial and temporal accuracy of predicted data. The effect of input values on the accuracy of WRF-FIRE simulations was evaluated to assess the capabilities of the new system for wildland fire in accurately forecasting fire behaviour. The results confirm that the use of accurate meteorological data and a custom fuel moisture content model is crucial to obtain precise simulations of fire behaviour.
\end{abstract}

\section{Introduction}

One of the main causes of destruction of the vegetation in the last years is wildfire. Wildfires are responsible for an important share of global greenhouse gas emission, particulate material and soil degradation. Forest fires are an issue of concern in most of 
the southern European countries. In Spain, the number of self-ignited fires has increased, also high temperatures and dry winds and vegetation help the fire propagation.

This study is developed into the PROMETEO project. It is focused on improving the capabilities to fight against the wildland fires in the Iberian Peninsula. It includes partners on all aspects related to the wildland fires. Helicopter branches, wildland fire simulations, spread of on-site sensors (temperature, humidity, etc.) use of permanent observational meteorological networks.

This paper describes an operational information system for wildland fires forecast over Spain and the results of preliminary simulations of a real fire. Our objective is to produce the best estimations of fuel moisture content (FMC) as a key input parameter into the wildland fire simulations.

FMC is usually classified as 'live' or 'dead' fuel. Live FMC is classified into wood and grass materials and the calculation process involves the estimations of land surface temperature (LST) and normalised difference vegetation index (NDVI) to estimate the live FMC for these two materials. The dead FMC is representing the wood material which is found in the forests as thin dead wood material and larger material. This is usually classified as $1 \mathrm{~h}, 10 \mathrm{~h}$ and $100 \mathrm{~h}$ materials. The $100 \mathrm{~h}$ material represents the large tree trunks on the floor. Since the observational FMC datasets are very scarce, we decided to use the wildland fire model to evaluate the proposed methodology to estimate the FMC values. The results from the fire model are compared with a real wildfire in Spain where we have the fire extension as a shape file.

To get detailed meteorological information we have used the mesoscale meteorological model weather and research forecasting (WRF) system developed by NCAR and others (Michalakes et al., 2001; Skamarock et al., 2005). WRF model is combined with a spread model by the level set method and the final system is called WRF-FIRE, which is the core of our system. WRF-FIRE is the successor to the CAWFE model (Clark et al., 1996). The algorithms for fire spread and fuel combustion in WRF-FIRE are based on the model of Rothermel (1972), using the fuel descriptors of Anderson (1982). Description of the WRF-FIRE physical model with the numerical algorithms used is presented in Mandel et al. (2011). In order for the propagation model to be efficient, forest fuels must be described in a particular way, in which the fuel characteristics are represented by certain average values. The set of these representative values is called 'fuel model'. We have used the 13 fuel models of Anderson (1982).

\section{Data and methods}

The core of the system is the WRF meteorological model, to model the fire behaviour we have the Sfire model, integrated into the WRF model. The fire model is two-way (online) coupled with the atmospheric model. Finally, a new FMC model has been developed and integrated into the WRF-FIRE system. We use the WRF assimilation capability to ingest measurement data.

\subsection{Operational wildfire system}

A mother domain has been setup with $86 \times 71$ grid cells and $15 \mathrm{~km} \times 15 \mathrm{~km}$ resolution over the Iberian Peninsula. One nested domain is required to scale the simulation down from the atmospheric mother domain to the atmospheric domain of $3 \mathrm{~km} \times 3 \mathrm{~km}$ with 
$30 \times 30$ grid cells; this domain is centred on the fire ignition line. The user can specify the time and location of a fire. The current WRF-FIRE model starts the fire from a given ignition point at a given time.

The meteorological information of the inner domain is interpolated to $200 \mathrm{~m}$. resolution. Finally, meteorological information is interpolated to the fire grid resolution with $20 \mathrm{~m}$. The limitations in computer time and available computational resources are the main causes for not having run the high spatial resolution runs $(200 \mathrm{~m})$. Each component is then interpolated separately to the grid cell centers of the subgrid ( $200 \mathrm{~m}$ and $20 \mathrm{~m}$ ) by bilinear interpolation from the $3 \mathrm{~km}$ domain.

The meteorological domains have 23 vertical layers. The global meteorological conditions are downloaded automatically from the global forecasts system (GFS) website, four times by day corresponding with the four initialisations of the GFS $(00,06$, 12, and 18). The objective is to have always the most recent data available. GFS data have a 6 hour output frequency. This domain architecture is based on the CPU time restrictions. In a more powerful computational platform, the resolution can be improved without problems.

The information is supplied through a web interface (http://indl.lma.fi.upm.es/ prometeo/) where users can view FMC data, temperature, winds, and fire evolution (Figure 1)

Figure 1 Web interface showing FMC (\%) map over Iberian Peninsula, $1 \mathrm{~km}$ resolution (interpoled from the $15 \mathrm{~km}$ resolution)

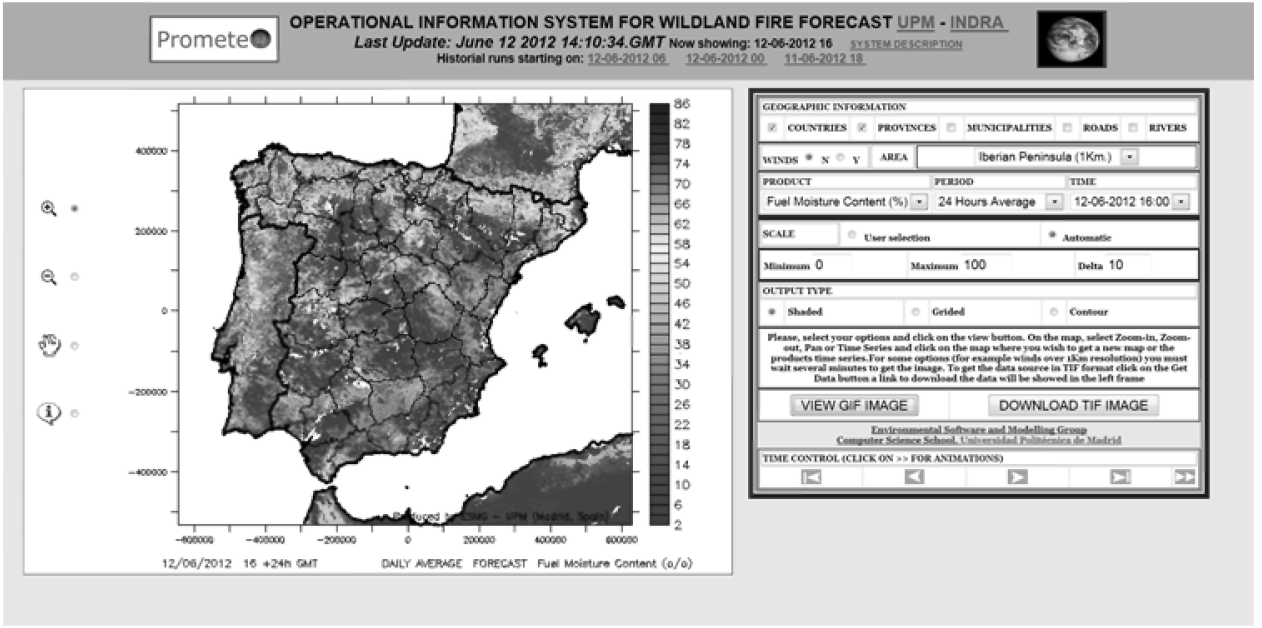

Note: 24 hours average (12/06/2012 16:00-13/06/2012 16:00).

The web interface shows the last four available simulations; from the right panel the user can select several options: geographic information, winds, domain, product, time period, colour scale. The user can also download a TIF file. Zoom capabilities can be used to focus over a specific area and it is possible obtain the results for a specific point, showing the temporal evolution of the selected product.

The system runs four times by day, starting at $00,06,12,18$ hours GMT, waiting for a fire notification. Simulations are run for 72 hours, with 24 hours of past time to make available the assimilate measurements. The number of measurement points depends on 
the fire area. After the fire is detected a wireless sensor network is activated around the fire line, with several meteorological sensors (5-10).

The operational scheme is summarised in the Figure 2. After 4 hours, the results are available with a forecast period of 44 hours. The computer platform is composed of two dual core and the system has been designed to be capable of running applications in robust, automatic model and with great reliability.

Figure 2 Operational scheme to forecast 44 hours of FMC, 4 times per day

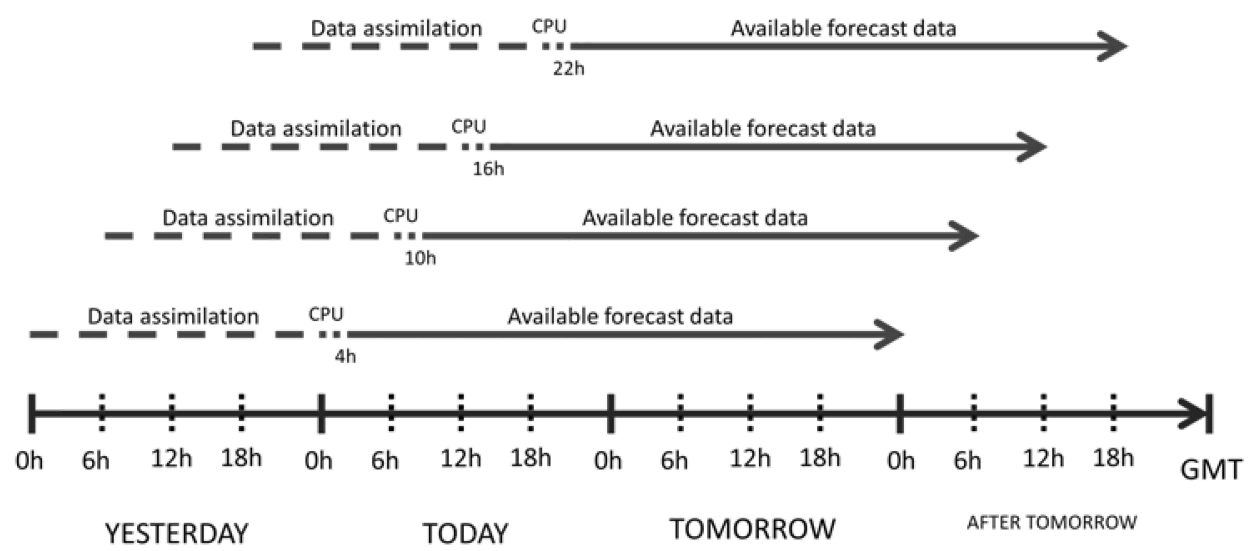

\subsection{FMC model}

McArthur (1966) developed a monogram for predicting the moisture content of cured grass, as part of his grassland fire danger metre (GFDM). The GFDM was converted to equations by Noble et al. (1980), where the prediction of fuel moisture is given by equation (1). This equation is used as base of our FMC calculations for fine dead fuel (1 hour dead fuel)

$$
m=\frac{97.9+4.06 H}{T+6}-0.00854 H_{\text {surf }}+\frac{3,000}{C}-30
$$

$H$ and $H_{\text {surf }}$ are the air humidity at $\mathbf{1 . 5}$ metres and surface levels, $T$ is the temperature at 1.5 metres and $C$ is the degree of curing (\%) and is considered as $100 \%$ for the calculation of dead FMC. This equation has now become more accepted than the original metres of McArthur. The GFDM has been found to perform well in predicting moisture content of aerial fuels in pine forest, mallee-heath and button-grass moorlands.

One of the problems in the prediction of FMC was the lack of consideration of the effects of condensation. In our system, we use a physical model to quantify the effects of nocturnal condensation on the moisture content of leaf litter (Viney and Hatton, 1990). Although the model is complex, because contains many input parameters, these input data can be gotten from the meteorological model WRF. Here is the equation:

$$
\Delta m=\frac{100}{W} \int_{\Delta t} \frac{G-N}{L+C_{p}\left(T-T_{\text {surf }}\right) /\left(Q-Q_{\text {surf }}\right)} d t
$$


where $W$ is the surface fuel mass, $G$ is the soil heat flux, $N$ is the net all-wave radiation flux, $L$ is the latent heat of vaporisation or sublimation, $C_{p}$ is the specific heat of air at constant pressure, $T$ and $T_{\text {sur }}$ are the temperature at 1.5 metres and surface levels and $Q$ and $Q_{\text {surf }}$ are the specific humidity at 1.5 metres and surface levels respectively.

In the case of 10 hours and 100 hours dead fuel, we have implemented into WRFFIRE the Nelson (2000) model modified to be operational (Bevins, 2004). Nelson equations describing the transfer of heat and moisture at the surface and within a stick are derived and then solved numerically. The model simulated change in moisture content and temperature in cylindrical wood sticks of any practical size based on 'heat loss' is equal to 'heat gain'.

FMC in live fuels is a critical factor driving wildfire susceptibility and wildfire behaviour. Live FMC is calculated following the correlation between vegetation greenness and its moisture content, consequently the NDVI can be used in estimating live FMC. Live FMC estimations can be improved by including the LST, because LST would be expected to increase in drier plants on account of reduced evapotranspiration. Specifically the ratio NDVI/LST was found to be very useful (Dasgupta et al., 2005).

The FMC module produces five FMC values, three for dead fuels $(1,10,100$ hours) and two for live fuels (wood and herbaceous fuels). These five values are aggregated based on a weight average. Weight factors are taken from other fire models as BehavePlus (Andrews, 2007), Farsite (Finney, 2004) and FlamMap (Finney, 2007). This aggregation uses information from the fuel model. The fuel model classification is made with information about land uses from 2000 Corine Land Cover (CLC-2000) with 100 metres of spatial resolution. The final fuel load map was derived by assigning a fuel class to each land uses. The allocation matrix is given in Table 1.

Table 1 Equivalence between fuel model classes and land uses from Corine Land Cover classification

\begin{tabular}{lc}
\hline Fuel model & CLC land uses \\
\hline 1-Short grass & $18,22,26,32,36,12,19,20$ \\
2-Timber grass and understory & $21,24,29,33,35$ \\
4-Chaparral & $25,27,15$ \\
6-Dormant brush & 22 \\
8-Compact timber litter & 23 \\
\hline
\end{tabular}

\section{Results}

A preliminary model validation was done on a real case of forest fire in the territory of Murcia (Spain). We have used our operational system based on WRF-FIRE to simulate a real wildland fire using our data sources in order to evaluate its ability to predict fire's propagation in real-time.

The fire ignited in a region of Murcia (Spain) on September 7, 2010 19:09. The final burned area is $7 \mathrm{~km}$ by $1 \mathrm{~km}$ after 9 hours. We have only the fire perimeter at the end of the fire event. In addition, it is known that fire-fighters have made numerous attacks on the fire in order to constrain the fire. As there is no precise data available on these attacks, we ran the simulation without taking into account the effect of the fire-fighters. 
The simulated area was discretised by a matrix of $350 \times 100$ cells; the cell resolution was $20 \mathrm{~m}$. The simulation was started at 19:00, 9 minutes before the estimated ignition points and stopped at 04:00 of the next day, so the total time of simulation was 9 hours.

We have the following data available: topography available from local authorities at up to 4 metre resolution. Land uses datasets available from Corine Land Cover (CLC 2000 ) at up to 100 metre resolution. The land uses were translated into fuel model, according to the Table 1.

Figure 3 represents the superimposition of the real fire and simulated fire at 1 hour, 3 hours, 6 hours and 9 hours after ignition. Real fire contour after 9 hours from ignition is displayed as light grey, and simulated contour fire is represented as dark grey colour. Arrows indicate the simulated winds from the meteorological model WRF. The fire increased rapidly after the three first hours. The fire was propagating according the wind direction and taking into account the available fuel. Figure 4 shows a top view of the 3D representation with the topography and the final burned area (dark) including wind vectors.

Figure 3 Observed fire line after 9 hours after ignition (light grey) to the modelled fire line (dark grey) at 1 (upper-left), 3 (upper-right), 6 (bottom-left), and 9 (bottom-right) hours and simulated vector winds

Final Observed fire line (grey). Modelled fire line at 1 hours (black)
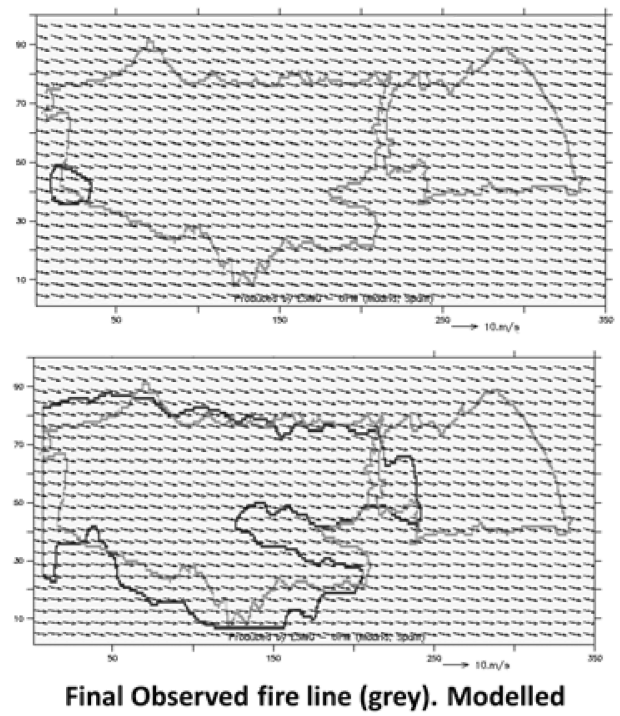
fire line at 6 hours (black)
Final Observed fire line (grey). Modelled fire line at 3 hours (black)
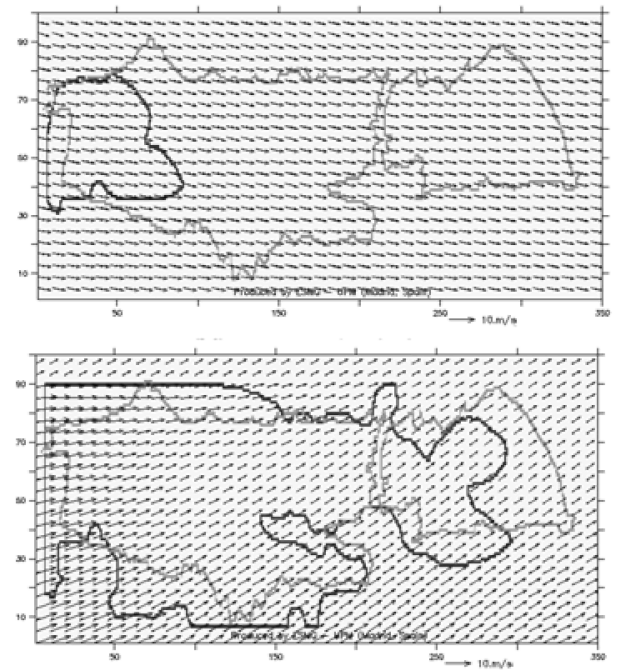

Final Observed fire line (grey). Modelled fire line at 9 hours (black)

An analysis of results in all grid cells from simulation and real data has been developed and $78.75 \%$ of the grid cells are well forecast, $13.93 \%$ are overestimated (simulated burned grid cells but in fact they were not burned) and $7.32 \%$ are underestimated (non-burned grid cells but in fact they were burned). The results of the simulation look good since few areas of the real fire do not appear to be burnt in the simulation and few areas, which were not burnt, are computed to be 'burnt'. Some differences are probably due to the attack of the fire fighters, because these actions are not modelled. The results of the simulation show a significant fit with the real data. 
Figure 4 Simulated final burned area (dark) after 9 hours over domain topography and wind vectors

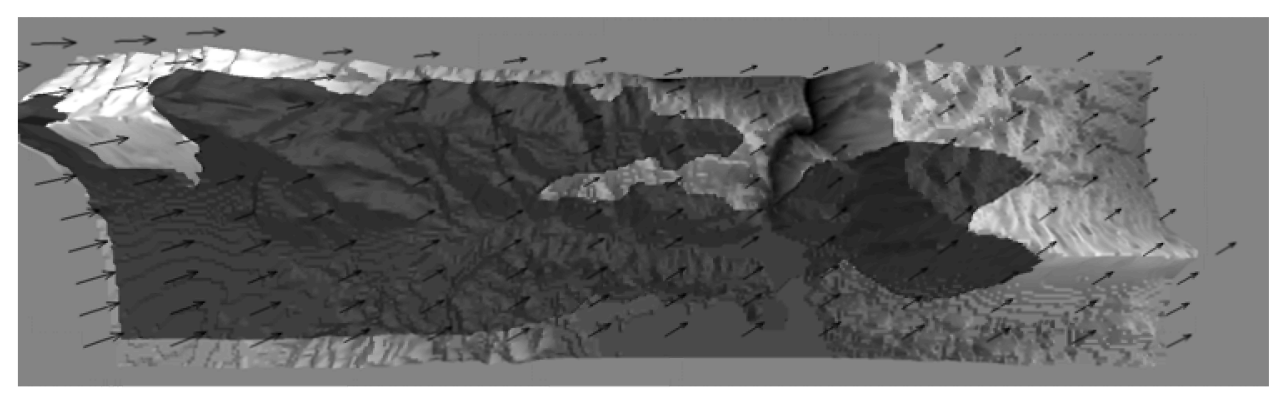

\section{Conclusions}

We have developed an operational and integrated simulation forecasting system for fires based on WRF-FIRE. Results show that the proposed system can produce realistic simulations using the geographical information available about the fire in a real case scenario. A graphical approach is used to compare the fire perimeters and burned areas. The comparisons show that simulation results are consistent with real data, so the system performs adequately in predicting the fire physics. The validation of the accuracy of the current fire propagation models is a big problem. The effect of external factors such as human interventions on the model cannot be accurately estimated. Further enhancements to the simulation system are planned based on more tests of real fire scenarios. For example, we will try to improve the meteorological information because the interpolation from $3 \mathrm{~km}$ to 20 metres cannot capture accurate local atmospheric features, but this is the only possibility to run the system quickly and an operational way at this time.

\section{Acknowledgements}

The authors thankfully acknowledge the computer resources, technical expertise and assistance provided by the Centro de Supercomputación y Visualización de Madrid (CESVIMA) and Centro para el Desarrollo Tecnológico Industrial (CDTI) and Indra Sistemas for supporting the project PROMETO. The authors thankfully acknowledge the forest fire reports and assistance provided by the Autonomous Community of Region of Murcia.

\section{References}

Anderson, H. (1982) Aids to Determining Fuel Models for Estimating Fire Behaviour, General Technical Report int-122' United States Department of Agriculture, Forest Service, Intermountain Forest and 233 Range Experiment Station.

Andrews, P.L. (2007) 'BehavePlus fire modeling system: past, present, and future', in Proceedings of 7 th Symposium on Fire and Forest Meteorological Society, 23-25 October, Bar Harbor, Maine. 
Bevins, C.D. (2004) 'Adapting Nelson's dead fuel moisture model for wildland fire modeling', BehavePlus fire modeling system Version 3.0 Users Guide, 145p.

Clark, T., Jenkins, M., Coen, J. and Packham, D. (1996) 'A coupled atmosphere-fire model: convective feedback on fire-line dynamics', Journal of Applied Meteorology, Vol. 35, No. 6, pp.875-901.

Dasgupta, S., Qu, J.J. and Hao, X. (2005) 'Evaluating remotely sensed live fuel moisture estimations for fire bejavior predictions', EastFIRE Conference 2005.

Finney, M.A. (2004) 'FARSITE: fire area simulator-model development and evaluation', Research Paper RMRS-RP-4 Revised, Ogden, UT: US Department of Agriculture, Forest Service, Rocky Mountain Research Station.

Finney, M.A. (2007) 'A computational method for optimising fuel treatment locations', International Journal of Wildland Fire, Vol. 16, No. 6, pp.702-711.

Mandel, J., Beezley, J. and Kochanski, A. (2011) 'Coupled atmosphere-wildland fire modeling with WRFfire', Geoscientific Model Development Discussions, Vol. 4, No. 3, pp.497-545.

McArthur, A.G. (1966) 'Weather and grassland fire behavior', Commonwealth of Australia, Department of National Development. Forestry and Timber Bureau, Leaflet No. 100.

Michalakes, J., Chen, S., Dudhia, J., Hart, L., Klemp, J., Middlecoff, J. and Skamarock, W. (2001) 'Development of a next generation regional weather research and forecast model. Developments in teracomputing', in Zwieflhofer, W. and Kreitz, N. (Eds.): Proceedings of the Ninth ECMWF Workshop on the Use of High Performance Computing in Meteorology, World Scientific, Singapore, pp.269-276.

Nelson Jr., R.M. (2000) 'Prediction of diurnal change in 1-h fuel stick moisture content', Canadian Journal Forest Research, Vol. 30, No. 7, pp.1071-1087.

Noble, I.R., Bary, G.A.V. and Gill, A.M. (1980) 'McArthur's fire-danger meters expressed as equations', Australian Journal of Ecology, Vol. 5, No. 2, pp.201-203.

Rothermel, R. (1972) A mathematical Model for Predicting Fire Spread in Wildland Fires, USDA Forest Service Research Paper INT-115.

Skamarock, W.C., Klemp, J.B., Dudhia, J., Gill, D., Barker, D., Wang, W. and Powers, J.G. (2005) A Description of the Advanced Research WRF Version 2, NCAR Technical Note NCAR/ TN-468+STR.

Viney, N.R. and Hatton, T.J. (1990) 'Modelling the effect of condensation on the moisture content of forest litter', Agricultural and Forest Meteorology, Vol. 51, No. 1, pp.51-62. 